\title{
А.Н. Гамидов
}

ГУ “ИОНХ им. В.Т. Зайцева НАМНУ”, г. Харьков, Шемахинская центральная районная больница, республика Азербайджан

\section{ПРОФИЛАКТИКА СПАЙКООБРАЗОВАНИЯ У БОЛЬНЫХ С РАСПРОСТРАНЕННЫМ ПЕРИТОНИТОМ}

\section{ПРОФІЛАКТИКА СПАЙКОУТВОРЕННЯ У ХВОРИХ 3 РОЗПОВСЮДЖЕНИМ ПЕРИТОНІТОМ}

Резюме. Проведена оцінка результатів лікування хворих на розповсюджений перитоніт, у яких з метою профілактики розвитку спайкового процесу під час оперативного втручання застосовувалась розроблена методика інтраопераційної обробки очеревини. Встановлено, що у хворих основної групи перистальтика відновлювалась в ранні терміни, позитивний вплив запропонованої методики лікування підтверджено даними УЗД. Дистанція руху внутрішніх органів у хворих основної групи становила $1,7 \pm 0,22$ см, у хворих групи порівняння - 0,86 $\pm 0,17$ см, тобто виявлення спайкоутворення у хворих основної групи була в 2 рази нижче, ніж в групі порівняння.

Ключові слова: розповсюджений перитоніт, спайкоутворення, профілактика.

Спаечный процесс после операций на органах брюшной полости привлекает неослабевающее внимание абдоминальных хирургов, что связано с высокой частотой его развития и большим количеством серьезных осложнений. Наиболее частым и грозным осложнением является острая спаечная кишечная непроходимость, составляющая более $40 \%$ среди различных видов приобретенной непроходимости кишечника, сопровождающаяся высоким уровнем летальности. Профилактика спаечной болезни (СБ) остается открытой проблемой еще и в связи со своей медико-социальной значимостью $[1,2]$. По частоте и числу рецидивов заболевания, функциональным нарушениям, СБ относится к категории тяжелых заболеваний, значительно ухудшающее качество жизни пациентов, как в эмоционально-психологическом, так и в социально-адаптационном плане [46].

В настоящее время большое клиническое значение приобретают профилактические меры. В последние годы в литературе появилось большое количество исследований, посвященных разработке методик интраоперационной профилактике адгезиообразования в брюшной полости, которая заключается в создании временных искусственных барьеров $[2,4,5]$.

Цель исследования: оценка разработанного метода интраоперационной профилактики спайкообразования у больных, оперированных по по-

воду распространенных форм перитонита.

Материалы и методы. Проанализированы результаты лечения 374 больных обоего пола, оперированных в клинике ГУ "ИОНХ им. В.Т. Зайцева НАМНУ” и Шемахинской центральной районной больнице (республика Азербайджан), по поводу разлитого перитонита, которые были разделены на две группь: сравнения (204 больных), лечившихся по общепринятым методикам; 174 пациента составили основную группу.

У всех больных основной группь применялась разработанная в клинике методика профилактики развития спаечного процесса. В качестве действуюшего вещества избран раствор Куриозина - препарата, содержащего гиалуронат ичинка. Вещество является стимулятором репараиии тканей, образуюшее естественный поддерживаюший каркас для клеток, участвуюший в заживлении тканей, повышаютий активность гранулоцитов и макрофагов, улучшающий микрочиркуляцию в тканях за счет улучшения ангиогенеза. Кроме того, препарат обладает бактериостатическим эффектом.

Разработанная методика заключается в следующем. После выполнения основного этапа оперативного вмешательства, тщательной санации брюшной полости растворами антисептиков и ее дренирования в брюшной полости оставляли тонкую ПВХ трубку, лапаротомия ушивалась до трубки. Перед затягиванием лигатур 
установленные дренажи перекрывались зажимами. После чего в брюшную через трубку вводили раствор Куриозина из расчета 10 мл препарата на 200 мл физиологического раствора $\mathrm{NaCl}$. Затем трубка извлекалась. Трубочные дренажи открывали через 6 часов от момента окончания операции.

Для оиенки эффективности предлагаемой методики нами проводилась динамическая ультразвуковая (УЗ) оценка спаечного прочесса, методика которой заключается в определении амплитуды скольжения петель кишечника как в продольной дистанции, которую проходят петли тонкой кишки или сальник при нормальном, форсированном ичкле вдох-вылох, а также при мануальной компрессии брюшной стенки Положительным семиотическим критерием обнаружения спаек являлась амплитуда скольжения петель кишечника менее 1,0 см. Когда имеет место прямолинейное движение двух точек наблюдения, признак считается негативным, тогда как если движений нет, или они имеют угловой характер, признак считается положительным, несмотря на амплитуду движений. Ультразвуковое исследование выполнялось в положении паџиентов на спине датчиком 7-7,5 МГц над околопупочной областью Наблюдение проводилось продольно и поперечно в течение нескольких дыхательных изиклов между границами передней брюшной стенки и аортокавального комплекса, с иелью выявления стабильного эхогенного фокуса, соответствующзего либо сальнику, либо киике, расстояние, которое этот фокус проходил (в продольной плоскости) записывалось, как скольжение внутренностей. Измерения движений кишечника производились как непосредственно в контакте с париетальной брюшиной, так и на более глубоком уровне. Ультразвуковое исследование выполнялось с помощьюю апnарата "Siemens Sonoline G50” (Германия), а также ультразвуковой сисmемы “Toshiba Aplio XG” (Япония).

Кроме того, в динамике оченивали признаки восстановления моторики кишечника на основании жалоб пациента и данных объективного осмотра.

Результаты исследования и их обсуждение. По данным контрольных инструментальных исследований через 96 часов от момента операции у больных основной группы в брюшной полости оставалось до 40\% первоначально введенного объема раствора Куриозина. Таким образом, несмотря на наличие дренажей, клинически значимый объем препарата сохранялся в брюшной полости на протяжении не менее чем трех суток.

В динамике исследований позитивный УЗ- контроль (амплитуда движения внутренних органов более 1,0 см) на 3-и сутки исследования отмечен у 83,3\% пациентов, на 7-е сутки исследования позитивный контроль отмечен у 77,7\% больных основной группы (рис.).

Сведения о восстановлении моторно-эвакуаторной функции кишечника по данным УЗИ представлены в таблице.

Как видно из приведенных в таблице данных, у больных основной группы имело место более раннее восстановление моторики кишечника. Положительное влияние предлагаемых методов хирургического лечения подтвердили УЗИ, проведенные на 10-е сутки послеоперационного

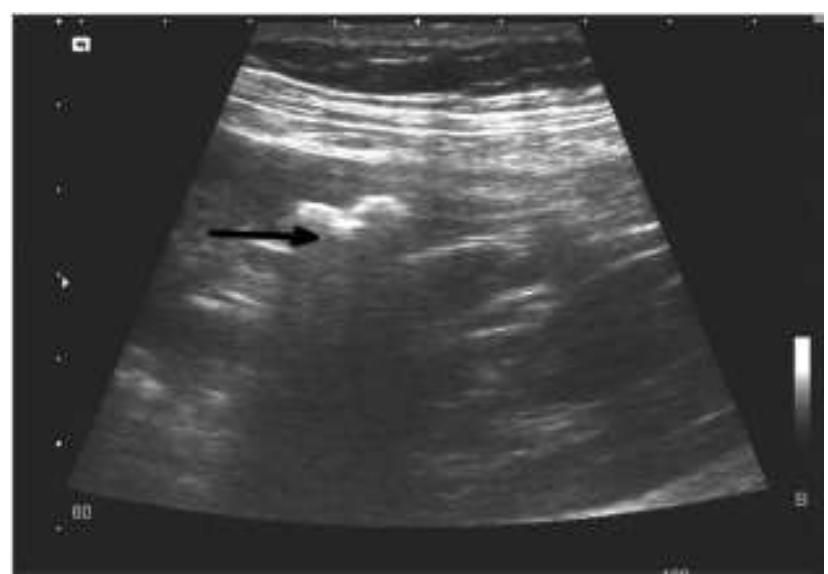

Рис. Больной Ф., 56 лет (и.б. № 413). УЗ исследование брюшной полости на третьи сутки послеоперационного периода. Умеренная дилатация петель тонкой кишки, амплитуда скольжения более 1,0 см

Таблица

Признаки нарушения моторно-эвакуаторной функции кишечника

\begin{tabular}{|l|c|c|}
\hline \multirow{2}{*}{$\begin{array}{l}\text { Признаки дис- } \\
\text { функции кишеч- }\end{array}$} & \multicolumn{2}{|c|}{ Группы больных } \\
\cline { 2 - 3 }$(\mathrm{n}=204)$ & $\begin{array}{c}\text { Основная } \\
(\mathrm{n}=174)\end{array}$ \\
\hline $\begin{array}{l}\text { Позднее восста- } \\
\text { новление пери- } \\
\text { стальтики }\end{array}$ & $99(48,5 \%)$ & $46(26,8 \%)$ \\
\hline $\begin{array}{l}\text { Позднее начало } \\
\text { отхождения газов }\end{array}$ & $86(42,7 \%)$ & $34(19,5 \%)$ \\
\hline $\begin{array}{l}\text { Потребность в } \\
\text { медикаментозной } \\
\text { стимуляции }\end{array}$ & $51(25 \%)$ & $21(12,2 \%)$ \\
\hline $\begin{array}{l}\text { Маятникообраз- } \\
\text { ная перисталь- } \\
\text { тика }\end{array}$ & $90(44,1 \%)$ & $25(14,6 \%)$ \\
\hline $\begin{array}{l}\text { Свободная жид- } \\
\text { кость }\end{array}$ & $117(57,4 \%)$ & $68(39,1 \%)$ \\
\hline $\begin{array}{l}\text { Расширение пе- } \\
\text { тель кишечника }\end{array}$ & $111(54,5 \%)$ & $38(22,1 \%)$ \\
\hline
\end{tabular}


периода. Дистанция скольжения внутренних органов у больных основной группы составила $1,7 \pm 0,22 \mathrm{~cm}$, у больных группы сравнения 0,86 $\pm 0,17$ см, то есть, выраженность спайкообразования у больных основной группы была в 2 раза ниже, чем в группе сравнения.

Вывод. Интраоперационная профилактика спайкообразования с применением Куриозина является эффективной методикой и может быть рекомендована к широкому применению.

\section{Список использованной литературы}

1. Ерюхин И.А. Инфекиия в хирургии. Старая проблема накануне нового тысячелетия (Часть 2) / И.А. Ерюхин // Вестн. хирургии. - 1998. - Т. 157, № 3. - С. 87-94. 2. Кулаков В.И. Пути профилактики образования послеоперачионных спаек у гинекологических больных / В.И. Кулаков, Л.В. Адамян, О.А. Мынбаев: Эндоскопия в диагностике и лечении патологии матки. - М., 1997. - Т. 2. - С. 245-254. 3. Васылюк М.Д. Хирургическое лечение острой спаечной кишечной не-проходимости у больных с большими и гигантскими грыжами. / М.Д. Васылюк, И.В. Биџка, С.М. Васылюк. // Скорая мед. помощь. - 2004. - Т. 5, № 3. - C. 73-74. 4. Профилактика спаек и связанных с ними осложнений при перитоните у детей / В.М. Державин, Е.И. Цветкова, М.Н. Иванова [и др.] // Хирургия. - 1989. - № 11. - С. 113-116. 5. Женчевский Р.А. Спаечная болезнь / Р.А. Женчевский. - М.: Медицина, 1989. - 192 с. 6. Диагностика и лечение острой кишечной непроходимости / П. Плевокас, В. Асеев, А. Римантас [и др.] // Скорая мед. помощь. - 2004. - T. 5, № 3. - C. 118-119.

\section{ПРОФИЛАКТИКА СПАЙКООБРАЗОВА- НИЯ У БОЛЬНЫХ С РАСПРОСТРАНЕН- НЫМ ПЕРИТОНИТОМ}

Резюме. Проведена оценка результатов лечения больных с распространенным перитонитом, которым с целью профилактики развития спаечного процесса во время операции применялась разработанная методика интраоперационной обработки брюшины. Установлено, что у больных основной группы имело место более раннее восстановление моторики кишечника. Положительное влияние предлагаемых методов хирургического лечения подтвердили УЗИ, проведенные в динамике. Дистанция скольжения внутренних органов у больных основной группы составила $1,7 \pm 0,22$ см, у больных группы сравнения $-0,86 \pm 0,17 \mathrm{~cm}$, то есть, выраженность спайкообразования у больных основной группы была в 2 раза ниже, чем в группе сравнения.

Ключевые слова: распространенный перитонит, спайкообразование, профилактика.

\section{PREVENTION OF COMMISSURE FORMA- TION IN PATIENTS WITH DIFFUSE PERITO- NITIS}

Abstract. Evaluation of the results of treatment of patients with diffuse peritonitis, who underwent the technique of peritoneal intraoperative cleansing in order to prevent the development of commissures during surgery, has been conducted. It was found that earlier recovery of intestinal motility was observed in patients from the main group. Ultrasound examination performed in the dynamics confirmed a positive impact of the proposed surgical treatment. Sliding distance of the internal organs in patients of the main group was $1,7 \pm 0,22 \mathrm{~cm}$, in patients from the comparison group $-0,86 \pm 0,17 \mathrm{~cm}$, i.e., the severity of commissures in patients from the main group was twice lower than that of the comparison group.

Key words: diffuse peritonitis, commissures, prevention.

State Establishment "V.T.Zaytsev Institute of General and Urgent Surgery, the National Academy of Medical Sciences of Ukraine", Kharkiv Shemakhinska Central District Hospital, Azerbaijan

Надійшла 25.02.2014 p. Рецензент - проф. Белоконев В.И. (Самара) 